\title{
Lung Mechanics and Exertional Dyspnea in Pulmonary Arterial Hypertension
}

\author{
Robert Naeije \\ Department of Cardiology, Erasme University Hospital, Brussels, Belgium
}

Shortness of breath dominates the symptomatology of pulmonary arterial hypertension $(\mathrm{PAH})$. Yet these patients hyperventilate all the time: during exercise, at rest, and even during sleep. Is this related to exercise intolerance? Not clearly so. Cardiopulmonary exercise testing in $\mathrm{PAH}$ consistently shows an increased ventilation to $\mathrm{CO}_{2}$ output slope but a preserved ventilatory reserve $[1,2]$. The cardiopulmonary exercise test profile of PAH much resembles that of congestive heart failure $(\mathrm{CHF})$ with decreased maximum (or peak) $\mathrm{O}_{2}$ uptake $\left(\mathrm{VO}_{2} \max \right)$, early lactic acidosis, decreased maximum $\mathrm{O}_{2}$ pulse, altered chronotropic responses and depressed $\mathrm{VO}_{2}$ kinetics, all typical of a cardiovascular limitation to aerobic exercise capacity $[1,2]$. Recent studies have pointed at a decreased skeletal muscle strength in PAH [3-5], but the clinical relevance of these observations is not clearly established [6]. Furthermore, patients with PAH generally have preserved pulmonary gas exchange and normal or near-normal lung volumes and airway resistances, which is not suggestive of a lung function limitation to exercise capacity $[6,7]$. Thus aerobic exercise capacity in PAH is mainly cardiac output-limited, and thus dependent on right ventricular adaptation to increased afterload [7].

In the present issue of Respiration, Richter et al. [8] challenge this established knowledge by showing that an

\section{KARGER}

E-Mail karger@karger.com

www.karger.com/res inspiratory capacity is often decreased in $\mathrm{PAH}$, and that this is associated with a decreased aerobic exercise capacity and a shorter life expectancy. Inspiratory capacity is the difference between total lung capacity and functional residual capacity, and as such increases in the presence of expiratory airflow limitation or dynamic hyperinflation. The authors measured in 50 patients with $\mathrm{PAH}$ an inspiratory capacity of $87 \pm 17 \%$, which was slightly decreased compared to normal, but with a variability as indicated by large standard deviations. An inspiratory capacity above the mean value was associated with a better 5-year survival. A multivariate analysis showed that inspiratory capacity at rest like pulmonary vascular resistance, functional class, the 6-min walk distance and $\mathrm{VO}_{2}$ max was an independent predictor of survival. However, the authors could not relate decreased resting inspiratory capacity to increased airway resistance or dynamic hyperinflation as assessed by the inspiratory capacity-to-total lung capacity ratio at rest or by the exercise-induced decrease in inspiratory capacity. Accordingly, they were hesitant about the interpretation of their results and invoked a combination of respiratory muscle weakness and insufficient diagnostic accuracy of resting inspiratory capacity.

A fascinating aspect of the report by Richter et al. [8] is that it introduces inspiratory capacity as a new biomarker
(C) 2014 S. Karger AG, Basel

0025-7931/14/0881-0016\$39.50/0
Robert Naeije

Department of Cardiology, Erasme University Hospital 808, Lennik Road BE-1070 Brussels (Belgium) E-Mail rnaeije@ulb.ac.be 
with prognostic relevance in PAH. This can only be to the satisfaction of the experts on the disease, as improved characterization of patient populations with biomarkers is useful for drug trial designs and management of hospital resources. However, the impact of adding a new biomarker to those already available on individual clinical decision making requires further dedicated studies.

As mentioned by Richter et al. [8], the prognostic impact of inspiratory capacity measurements has been reported previously in chronic obstructive pulmonary disease and in CHF. In chronic obstructive pulmonary disease, decreased inspiratory capacity reflects dynamic hyperinflation related to the severity of airflow obstruction [9]. In CHF, decreased inspiratory capacity is thought to reflect dynamic hyperinflation in the context of small airway obstruction on interstitial lung edema related to heart failure severity [10]. Why would the inspiratory capacity be decreased in PAH? Patients with $\mathrm{PAH}$ have no pulmonary congestion but may present with peripheral airway obstruction probably due to a compression of bronchioles by dilated small arteries [11]. Depending on the breathing pattern and the level of ventilation, which is increased in proportion to PAH severity, this may be a cause of dynamic hyperinflation and associated worsen- ing of dyspnea during exercise $[12,13]$. However, dynamic hyperinflation does not occur in all PAH patients, and whether or not it contributes to a limitation of aerobic exercise capacity has not been established.

The diagnosis of dynamic hyperinflation on the basis of a decreased inspiratory capacity alone is insufficient. The measurement is clearly dependent on the breathing pattern. In healthy volunteers, an exercise-induced increase in ventilation increases [13] or does not affect [14] inspiratory capacity, while metronome-paced tachypnea decreases inspiratory capacity [14]. The measurement is also volitional and respiratory muscle strength-dependent, which can to some extent be corrected by total lung capacity. But, as underscored by Richter et al. [8], this does not exclude a contribution of respiratory muscle weakness previously shown to occur in $\mathrm{PAH}$ [3]. The diagnosis of dynamic hyperinflation requires measurements of all lung volumes and inspection of flow-volume loops.

Richter et al. [8] are to be commended for introducing inspiratory capacity as a new biomarker of prognostic relevance in PAH. Their results pave the way for studies aimed at a better understanding of the mechanisms of resting and exercise-induced dyspnea in PAH patients.

\section{References}

-1 Sun XG, Hansen EJ, Oudiz R, Wasserman K: Exercise pathophysiology in patients with primary pulmonary hypertension. Circulation 2001;104:429-435.

-2 Deboeck G, Niset G, Lamotte M, Vachiéry JL, Naeije R: Cardiopulmonary exercise testing in pulmonary arterial hypertension and in congestive heart failure: what are the differences? Eur Respir J 2004;23:747-751.

-3 Meyer FJ, Lossnitzer D, Kristen AV, Schoene AM, Kübler W, Katus HA, Borst MM: Respiratory muscle dysfunction in idiopathic pulmonary arterial hypertension. Eur Respir J 2005;25:125-130.

4 Bauer R, Dehnert C, Schoene P, et al: Skeletal muscle dysfunction in patients with idiopathic pulmonary arterial hypertension. Respir Med 2007;101:2366-2369.
5 Mainguy V, Maltais F, Saey D, et al: Peripheral muscle dysfunction in idiopathic pulmonary arterial hypertension. Thorax 2010;65: 113-117.

-6 Naeije R, van de Borne P: Clinical relevance of autonomic nervous system disturbances in pulmonary arterial hypertension. Eur Respir J 2009;34:792-794

7 Mélot C, Naeije R: Pulmonary vascular diseases. Compr Physiol 2011;1:593-619.

8 Richter MJ, Tiede H, Morty RE, et al: The prognostic significance of inspiratory capacity in pulmonary arterial hypertension. Respiration, $2014 ; 88: 24-30$.

$\checkmark 9$ O'Donnell DE, Webb KA: Exertional breathlessness in patients with chronic airflow obstruction. The role of lung hyperinflation. Am Rev Respir Dis 1993;148:1351-1357.

10 Nanas S, Nanas J, Papazachou O, et al: Resting lung function and hemodynamic parameters as predictors of exercise capacity in patients with chronic heart failure. Chest 2003;123: 1386-1393.
1 Meyer FJ, Ewert R, Hoeper MM, et al: Peripheral airway obstruction in primary pulmonary hypertension. Thorax 2002;57:473-476.

12 Laveneziana P, Garcia G, Joureau B, et al: Dynamic respiratory mechanics and exertional dyspnea in pulmonary arterial hypertension. Eur Respir J 2013;41:578-587.

13 Richter MJ, Voswinckel R, Tiede H, et al: Dynamic hyperinflation during exercise in patients with precapillary pulmonary hypertension. Respir Med 2012;106:308-313.

$>14$ Cooper CB, Calligaro GL, Quinn MM, et al: Determinants of dynamic hyperinflation during metronome-paced tachypnea in COPD and normal subjects. Respir Physiol Neurobiol 2014;190:76-80. 